\title{
FLOW BEHAVIOR OF THREE 625-TYPE ALLOYS DURING HIGH TEMPERATURE DEFORMATION
}

\author{
D. Zhao, P. K. Chaudhury, R.B. Frank*, and L.A. Jackman** \\ Concurrent Technologies Corporation, 1450 Scalp Avenue, Johnstown, PA 15904 \\ ${ }^{*}$ Carpenter Technology Corporation, P.O. Box 14662, Reading, PA 19612 \\ **Teledyne Allvac, 2020 Ashcraft Avenue, Monroe, NC 28110
}

\begin{abstract}
Three 625-type superalloys have been tested in compression over wide ranges of temperatures $(900-1150 \mathrm{C})$ and strain rates $\left(0.001-20 \mathrm{~s}^{-1}\right)$ to investigate the effects of chemical composition on both flow behavior and the resulting microstructure. Initial flow hardening followed by flow softening prevails at all temperatures and strain rates. Dynamic recrystallization has been identified as the main softening mechanism. Constitutive equations are determined from the flow data at a constant strain for the entire range of temperatures and strain rates tested. Asdeformed microstructures, in terms of percentage recrystallization and recrystallized grain size, have been mapped for all three alloys. It has been demonstrated that appropriate selection and control of processing parameters can produce very fine-grain and uniform microstructure required in many applications. Combined information on constitutive equations and asdeformed microstructures will assist the selection of deformation processing parameters to obtain desired microstructures.
\end{abstract}

This work was conducted by the National Center for Excellence in Metalworking Technology, operated by Concurrent Technologies Corporation, under contract to the U.S. Navy as part of the U.S. Navy Manufacturing Technology Program.

\footnotetext{
Superalloys 718, 625, 706 and Various Derivatives Edited by E.A. Loria

The Minerals, Metals \& Materials Socicty, 1994
} 


\section{Introduction}

Nickel-base alloy 625 has excellent corrosion resistance for both high temperature and aqueous corrosion applications. Typical high temperature applications include aircraft thrust reversers and sound suppression devices, and typical corrosion related applications are wet scrubbers, heat exchangers, and piping. The alloy possesses high strength with outstanding fatigue properties. However, its high strength is typically achieved through cold-working, and this practice is difficult when the section size of the part is large. As a result, Custom Age 625 PLUS* alloy was developed [1] to achieve high strength through age-hardening. Compared to nominal alloy 625, Custom Age 625 PLUS alloy has higher Ti, lower C, and optimized levels of $\mathrm{Cr}, \mathrm{Mo}$, and $\mathrm{Fe}$ to promote age-hardening while maintaining the corrosion resistance of coldworked alloy 625 in many environments [1].

Due to the availability of post-deformation heat treatment for strength, Custom Age 625 PLUS alloy can be hot-worked to finished size since warm- or cold-working is not necessary. In order to design and optimize hot working processes for this alloy, quantitative information on flow stress as a function of temperature and strain rate is desirable to engineers. It is important to model the hot working process for equipment selection, processing parameter optimization and die design. In addition to flow data, the as-deformed microstructures are also of interest. The as-deformed microstructure forms the basis of heat treatment processes.

In this investigation, flow behavior of Custom Age 625 PLUS alloy was studied by conducting compression tests at various temperatures and strain rates. Flow curves at test conditions were generated, and the constitutive equations were determined. Microstructural changes during high temperature deformation were also characterized, and a microstructure map was developed. In comparison to Custom Agc 625 PLUS alloy, Pyromet* 625 alloy produced by Carpenter Technology Corporation, and Nickelvac** 625 alloy by Teledyne Allvac, were also tested and analyzed to determine the effect of chemical composition on the flow behavior and as-deformed microstructure. The preferred processing conditions in terms of temperature and strain rate are recommended for all three alloys.

\section{Material and Experimental Procedure}

The materials used in this investigation were commercially available Custom Age 625 PLUS alloy and Pyromet 625 alloy, provided by Carpenter Technology Corporation, and Nickelvac 625 alloy, provided by Teledyne Allvac. The Custom Age 625 PLUS alloy bar was approximately $25 \mathrm{~mm}$ in diameter, and the other two 625 alloy bars were $19 \mathrm{~mm}$ in diameter. The Custom Age 625 PLUS alloy was solutionized at $1035 \mathrm{C}$, air-cooled, and aged. Because of a high temperature solution treatment, the Custom Age 625 PLUS alloy (Figure 1a) consists of equiaxed grains with an average grain size of $62 \mu \mathrm{m}$. There are also some fine inter- and intragranular carbide precipitates. The Pyromet 625 alloy was annealed at $925 \mathrm{C}$ and waterquenched. The microstructure consists of fine equiaxed grains of $12 \mu \mathrm{m}$ in average size. Very fine carbide precipitates delineate the grain boundaries mostly in the direction of hot-rolling. Some larger carbonitride particles are also dispersed in the matrix. The Nickelvac 625 alloy was also annealed at $925 \mathrm{C}$ and water-quenched, and the microstructure has a similar average grain size of $8 \mu \mathrm{m}$ and a more uniform distribution of the fine carbide precipitates along the grain boundaries. Extensive annealing twins are present in all three materials.

The chemical compositions are shown in Table I. The Custom Age 625 PLUS alloy contains considerably higher $\mathrm{Ti}$ and lower $\mathrm{C}$ than the other two 625 alloys. The composition of Nickelvac 625 alloy is similar to that of Pyromet 625 alloy except that the former has lower $\mathrm{Nb}$ and higher $\mathrm{Fe}$ content.

Cylindrical compression test specimens with a diameter of $12.7 \mathrm{~mm}$ and a height of $15.9 \mathrm{~mm}$ were machined from the as-received bars. Isothermal hot compression tests were conducted in

\footnotetext{
${ }^{*}$ Registered trademark licensed to Carpenter Technology Corporation by its subsidiary CRS holdings, Inc.

** Registered trademark of Teledyne Allvac.
} 
vacuum on a high speed servohydraulic MTS machine equipped with a high temperature (up to $2000 \mathrm{C}$ ) vacuum furnace. The range of test temperatures covered the range of present industrial practice $[2,3]$, i.e. from 900 to 1150 C, except for Custom Age 625 PLUS alloy where 950 was the lowest temperature. The strain rates were $0.001,0.01,0.05,0.1,0.5,1,5$, and $20 \mathrm{~s}^{-1}$. The specimens were compressed to a true strain of 0.8 for Custom Age 625 PLUS alloy and Pyromet 625 alloy, and 0.6 for the Nickelvac 625 alloy.

Prior to compression, the specimens were soaked at the test temperature for 10 minutes to avoid temperature gradients within the specimen. Load and stroke data from the tests were acquired by a computer and later converted to true stress-true strain curves. Immediately after the compression test, the specimens were quenched with forced helium gas to retain the deformed microstructure.

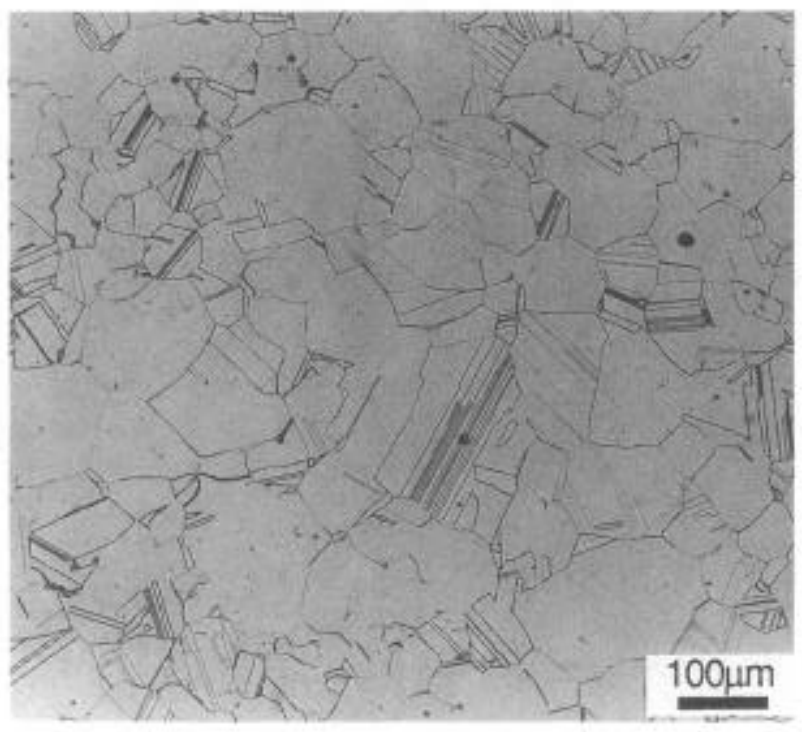

(a)



(b)

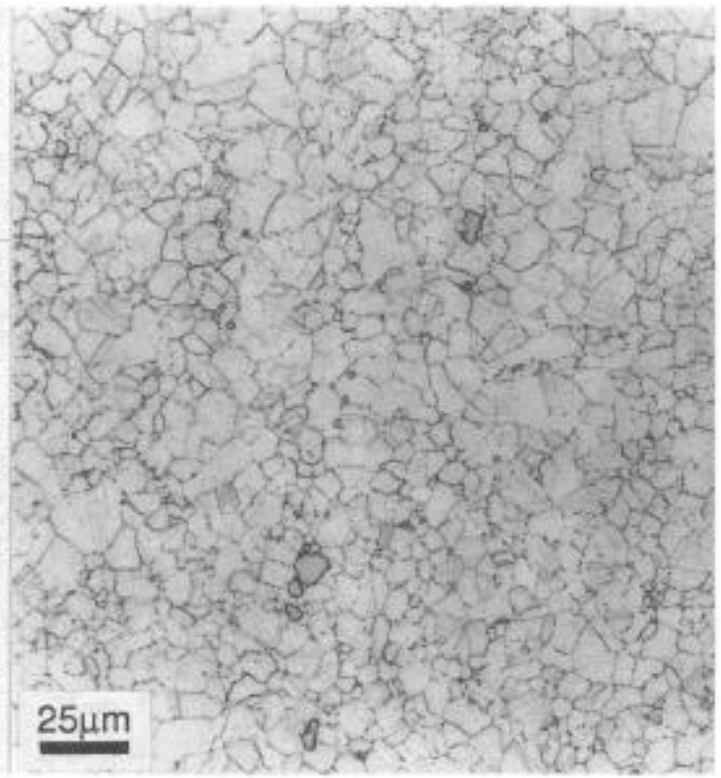

(c)

Figure 1 - As-received microstructures, (a) Custom Age 625 PLUS alloy; (b) Pyromet 625 alloy; (c) Nickelvac 625 alloy from Teledyne Allvac.

The initial cooling rate (from test temperature to $600 \mathrm{C}$ ), measured using a thermocouple inserted in the specimens, was $300-500 \mathrm{C} / \mathrm{min}$, depending on the test temperature. The deformed specimens were sectioned through the longitudinal axis and metallographically prepared. The microstructural analyses using optical microscopy were conducted at Concurrent Technologies Corporation, Carpenter Technology Corporation, and Teledyne Allvac. The photomicrographs presented were taken from the center of the longitudinal sections. For percentage of recrystallization, five fields were counted using a 100 -point grid, while for recrystallized grain 
size, three to four fields were examined for measurement by the linear intercept method using a concentric circle grid totalling $500 \mathrm{~mm}$ in length.

Table I Chemical Composition of As-received Materials (wt\%)

\begin{tabular}{|c|c|c|c|c|c|c|c|c|c|c|c|c|}
\hline Alloy & $\mathrm{C}$ & $\mathrm{Mn}$ & $\mathrm{Si}$ & $\mathrm{P}$ & $\mathrm{S}$ & $\mathrm{Cr}$ & $\mathrm{Ni}$ & $\mathrm{Mo}$ & $\mathrm{Al}$ & $\mathrm{Ti}$ & $\mathrm{Nb}$ & $\mathrm{Fe}$ \\
\hline \hline $\begin{array}{c}\text { Custom Age } \\
\text { 625 PLUS }\end{array}$ & .007 & .01 & .05 & .002 & .001 & 21.1 & 60.7 & 8.06 & .2 & 1.35 & 3.39 & 5.08 \\
\hline Pyromet 625 & .042 & .04 & .09 & .003 & .003 & 21.9 & 62.1 & 8.84 & .18 & .25 & 3.96 & 2.38 \\
\hline Nickelvac 625 & .051 & .11 & .08 & .009 & .0002 & 20.9 & 62.1 & 8.41 & .29 & .29 & 3.32 & 4.19 \\
\hline
\end{tabular}

$\underline{\text { Results }}$

True stress-true strain curves at each test condition and representative microstructures have been reported elsewhere [4-6]. Figures 2, 3 and 4 show the typical flow curves for Custom Age 625 PLUS alloy, Pyromet 625 alloy, and Nickelvac 625 alloy, respectively. The flow curves showed basically two features: (1) flow softening after initial flow hardening at most test conditions; and (2) slight flow hardening continued after the first peak at high temperatures and low strain rates such as $1150 \mathrm{C}$ and $0.001 \mathrm{~s}^{-1}$. The level of flow stresses was comparable among all three alloys.

Examination of the as-deformed microstructures revealed different results for the three alloys. Nickelvac 625 alloy exhibited a lower temperature for complete dynamic recrystallization (DRX). The material was essentially completely recrystallized at temperatures as low as $900 \mathrm{C}$ (Figure 5a). Pyromet 625 alloy, in contrast, was only partially recrystallized at the same condition (Figure 5b). A lower percentage of recrystallization was observed for Custom Age 625 PLUS alloy at even higher temperature, $950 \mathrm{C}$, Figure $5 \mathrm{c}$. Complete recrystallization did not occur until 1050C for Custom Age 625 PLUS alloy and $1000 \mathrm{C}$ for Pyromet 625 alloy.

The grain boundary carbide precipitates in the two 625 alloys caused some resistance to necklacing at the onset of recrystallization. Figure $5 \mathrm{~b}$ shows a photomicrograph of partially recrystallized Pyromet 625 alloy deformed at $900 \mathrm{C}$ and $1.0 \mathrm{~s}^{-1}$. The boundaries of deformed grains without closely spaced fine precipitates show necklacing, while those with precipitates show very limited necklacing. This observation is consistent with profuse necklacing (Figure 5c) in Custom Age 625 PLUS alloy which has few grain boundary carbides due to very low C content in the alloy. Further, in completely recrystallized structures deformed at low temperatures and high strain rates, the grain boundary precipitates remain at the prior grain boundaries. At high temperatures and low strain rates $\left(0.001 \mathrm{~s}^{-1}\right)$, however, these precipitates coarsen as expected.

Post-deformation microstructure also revealed different grain size and grain growth rate after complete recrystallization. Figure 6 shows the microstructural map which summarizes the microstructures at all test conditions for Custom Age 625 PLUS alloy. Either partially or completely recrystallized microstructures were observed. For partially recrystallized microstructures, the percentage of recrystallization and, in some cases, the average recrystallized grain size are reported, while for completely recrystallized microstructures, only the average grain size is identified. This map gives important guidelines for hot working process design. Similar maps were also constructed for Pyromet 625 alloy (Figure 7) and Nickelvac 625 alloy (Figure 8). Although Nickelvac 625 alloy recrystallized at the lowest temperature, Pyromet 625 alloy exhibited the finest recrystallized grain size. At the highest temperature $(1150 \mathrm{C})$ and lowest strain rate $\left(0.001 \mathrm{~s}^{-1}\right)$, the condition at which grain coarsening is most likely to occur, Pyromet 625 alloy and Nickelvac 625 alloy had an average grain size of 62 and $85 \mu \mathrm{m}$ respectively, whereas the Custom Age 625 PLUS alloy had a grain size averaging $113 \mu \mathrm{m}$. The percentage DRX increased with increasing temperature at a given strain rate. However, the effect of strain rate is more complex, in general showing lowest percentage DRX at intermediate strain rates except at $900 \mathrm{C}$ for Pyromet 625 alloy. 

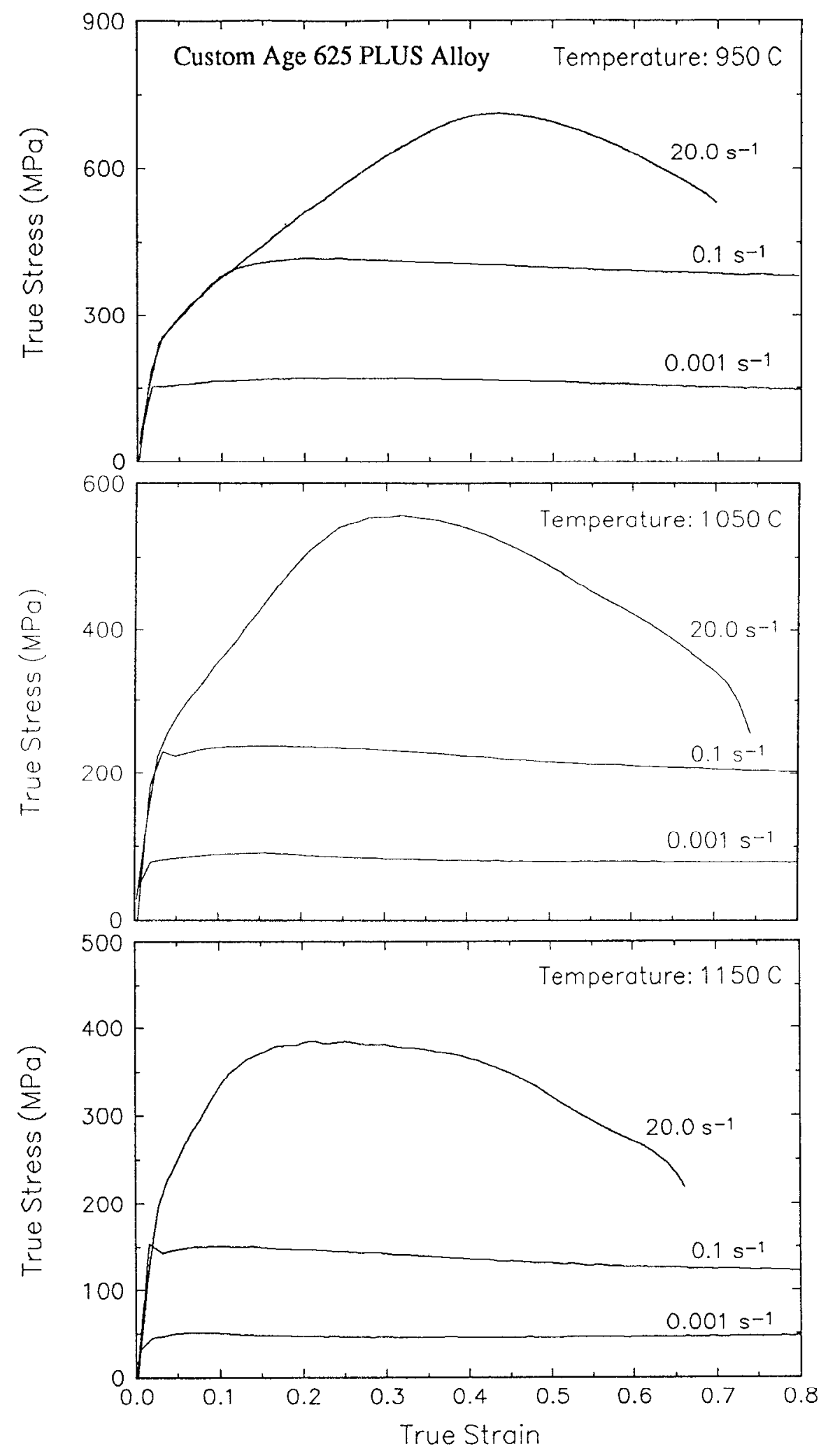

Figure 2 - Flow curves at different temperatures and strain rates for Custom Age 625 PLUS alloy. 

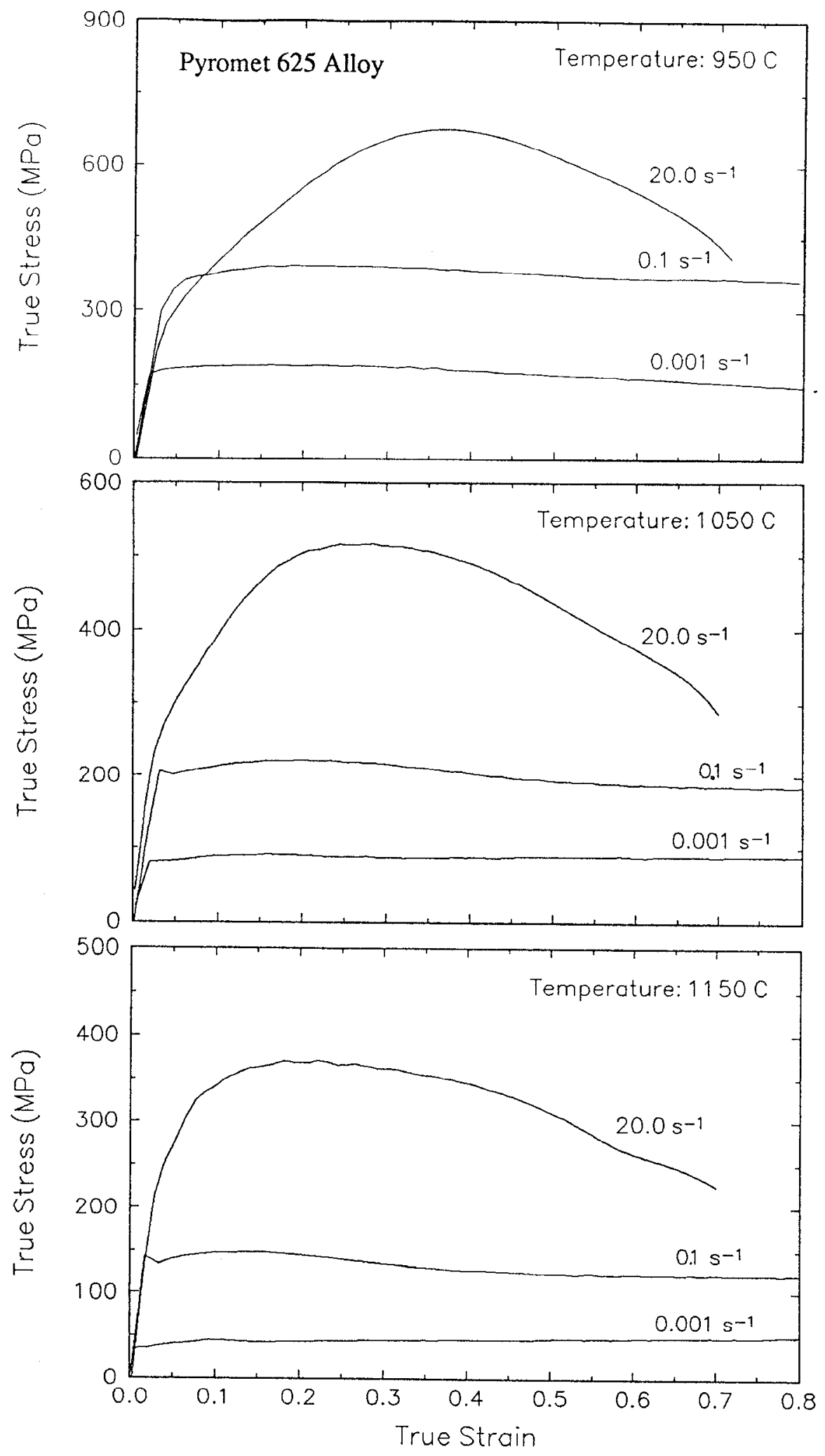

Figure 3 - Flow curves at different temperatures and strain rates for Pyromet 625 alloy. 

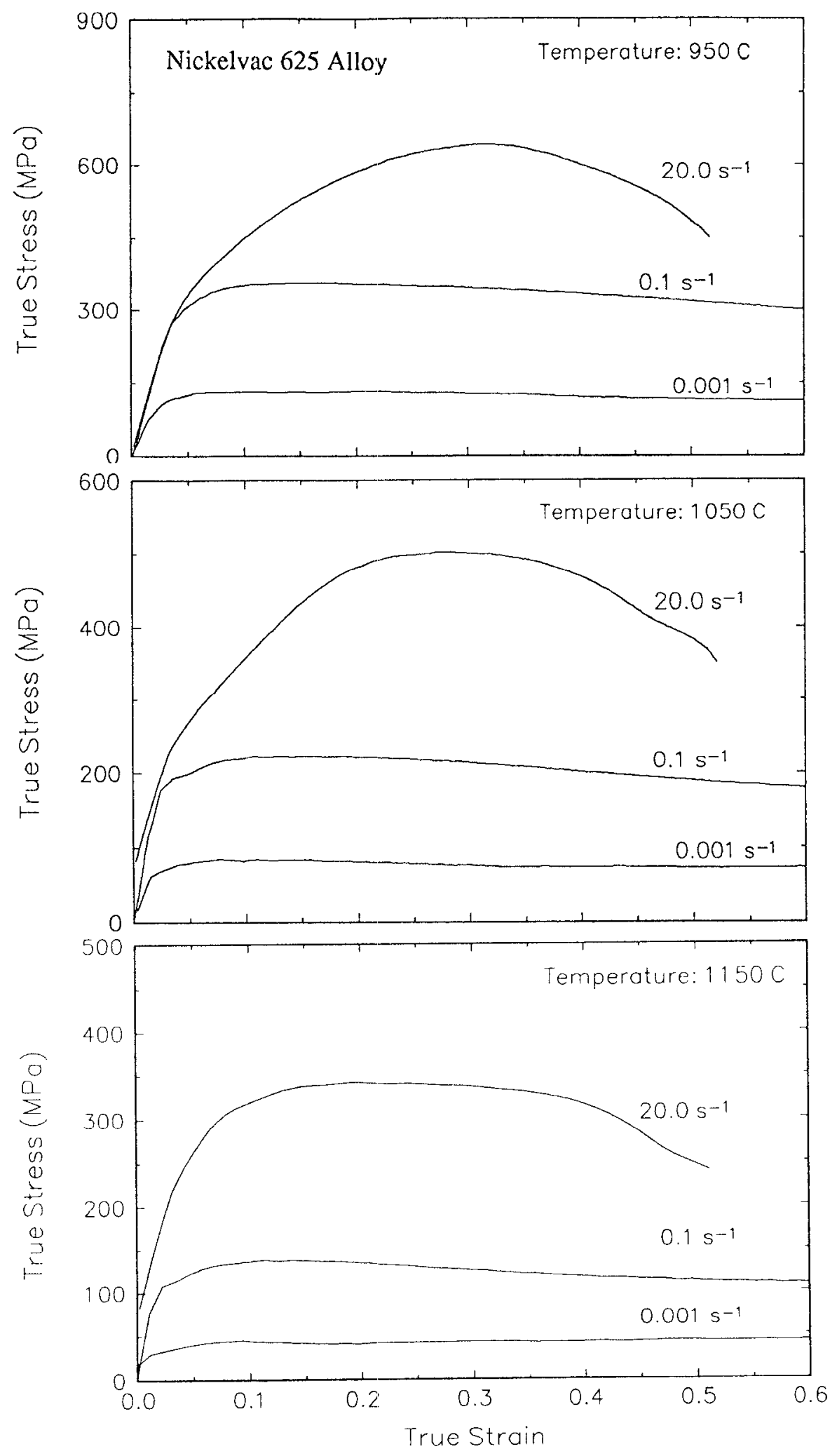

Figure 4 - Flow curves at different temperatures and strain rates for Nickelvac 625 alloy. 


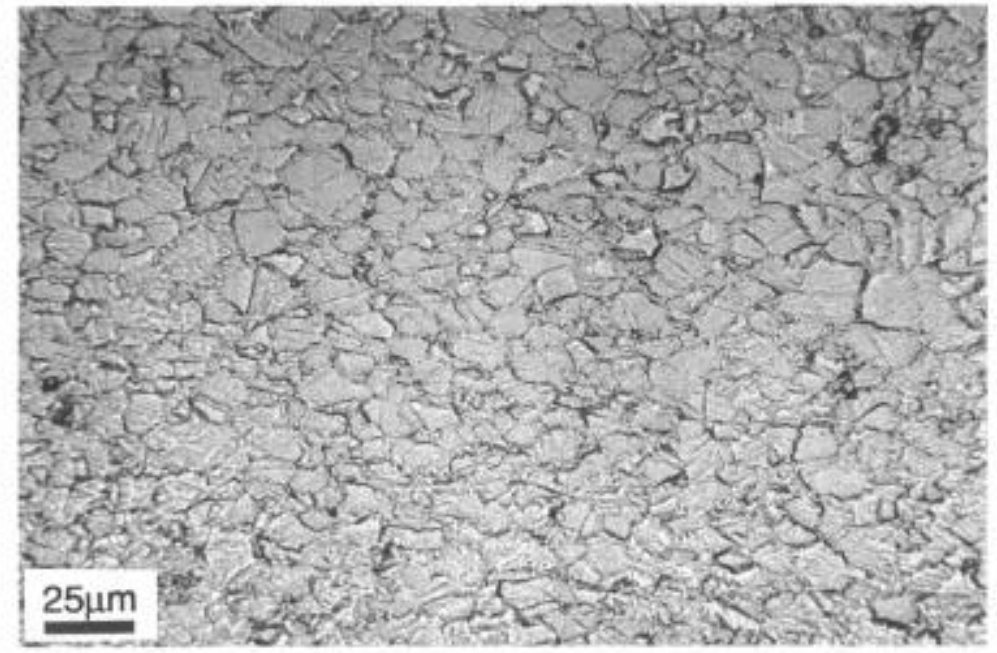

(a)

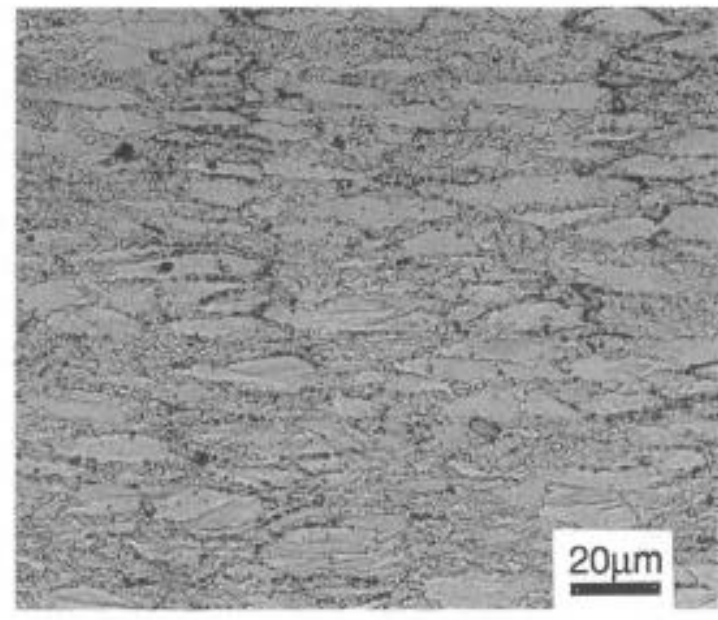

(b)

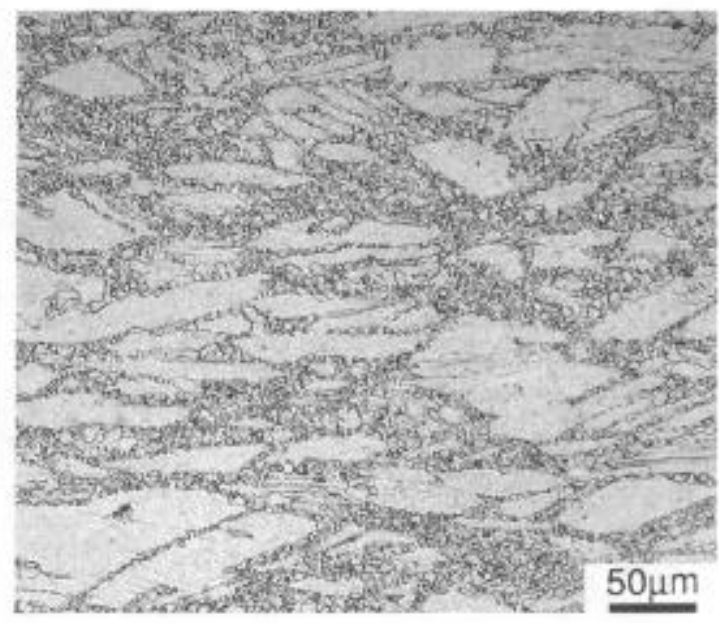

(c)

Figure 5- Optical micrograph of the deformed specimen (a) Nickelvac 625 alloy, $900 \mathrm{C}$ and 1 $\mathrm{s}^{-\mathrm{P}}$, deformed to a true strain of 0.6 , showing complete recrystallization, (b) Pyromet 625 alloy, $900 \mathrm{C}$ and $1 \mathrm{~s}^{-1}$, deformed to a true strain of 0.8 , showing partial recrystallization, and (c) Custom Age 625 PLUS alloy, $950 \mathrm{C}$ and $1 \mathrm{~s}^{-1}$, deformed to a true strain of 0.8 , showing partial recrystallization.

\section{Discussion}

A constitutive relation describing the strain rate and temperature dependence of flow stress for these alloys can be represented by the empirical equation at a constant strain:

$$
\sigma=A \dot{\varepsilon}^{m} \exp \left(\frac{Q}{R T}\right)
$$

where $\sigma$ is flow stress, $\dot{\varepsilon}$ is strain rate, $\mathrm{A}$ is a strength coefficient which is structure dependent, $\mathrm{Q}$ is the activation energy for plastic deformation, and $\mathrm{m}$ is the strain rate sensitivity. 


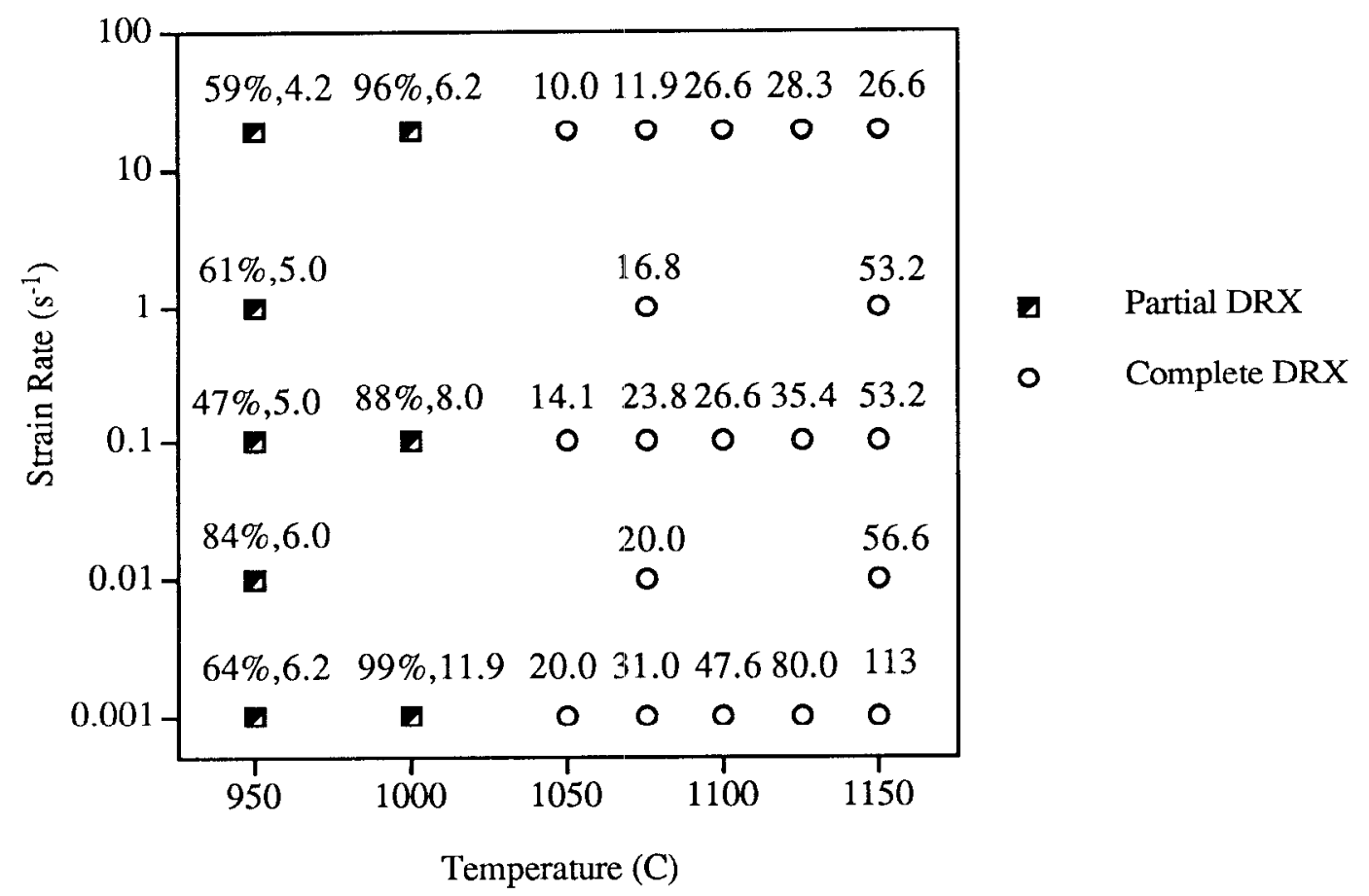

Figure 6 - Microstructural map summarizing as-deformed microstructures for Custom Age 625 PLUS alloy deformed to a true strain of 0.8 ; percentage of DRX is shown for partially recrystallized microstructures, and recrystallized grain size is shown in $\mu \mathrm{m}$.

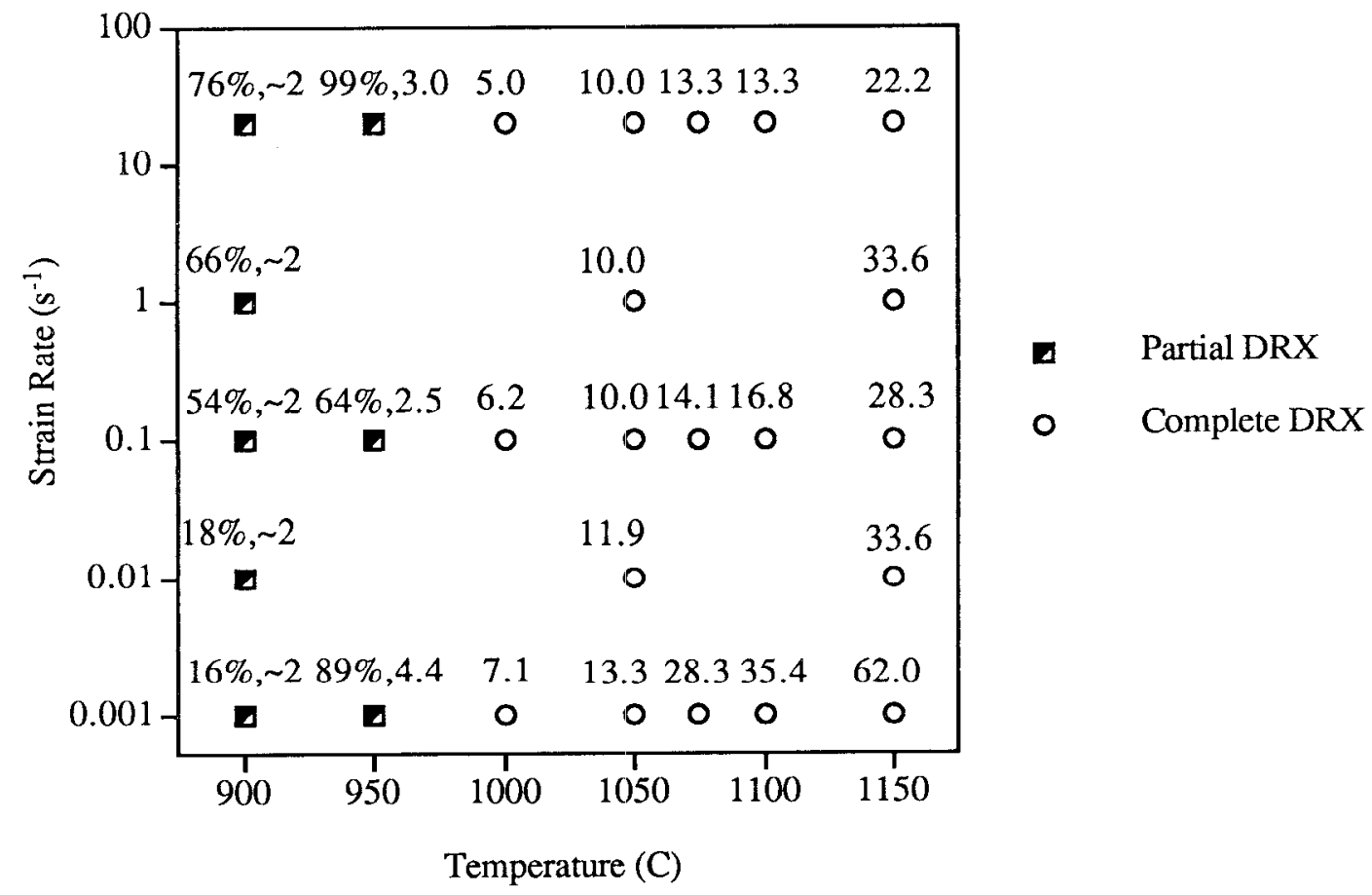

Figure 7 - Microstructural map summarizing as-deformed microstructures for Pyromet 625 alloy deformed to a true strain of 0.8 ; percentage of DRX is shown for partially recrystallized microstructures, and recrystallized grain size is shown in $\mu \mathrm{m}$. 


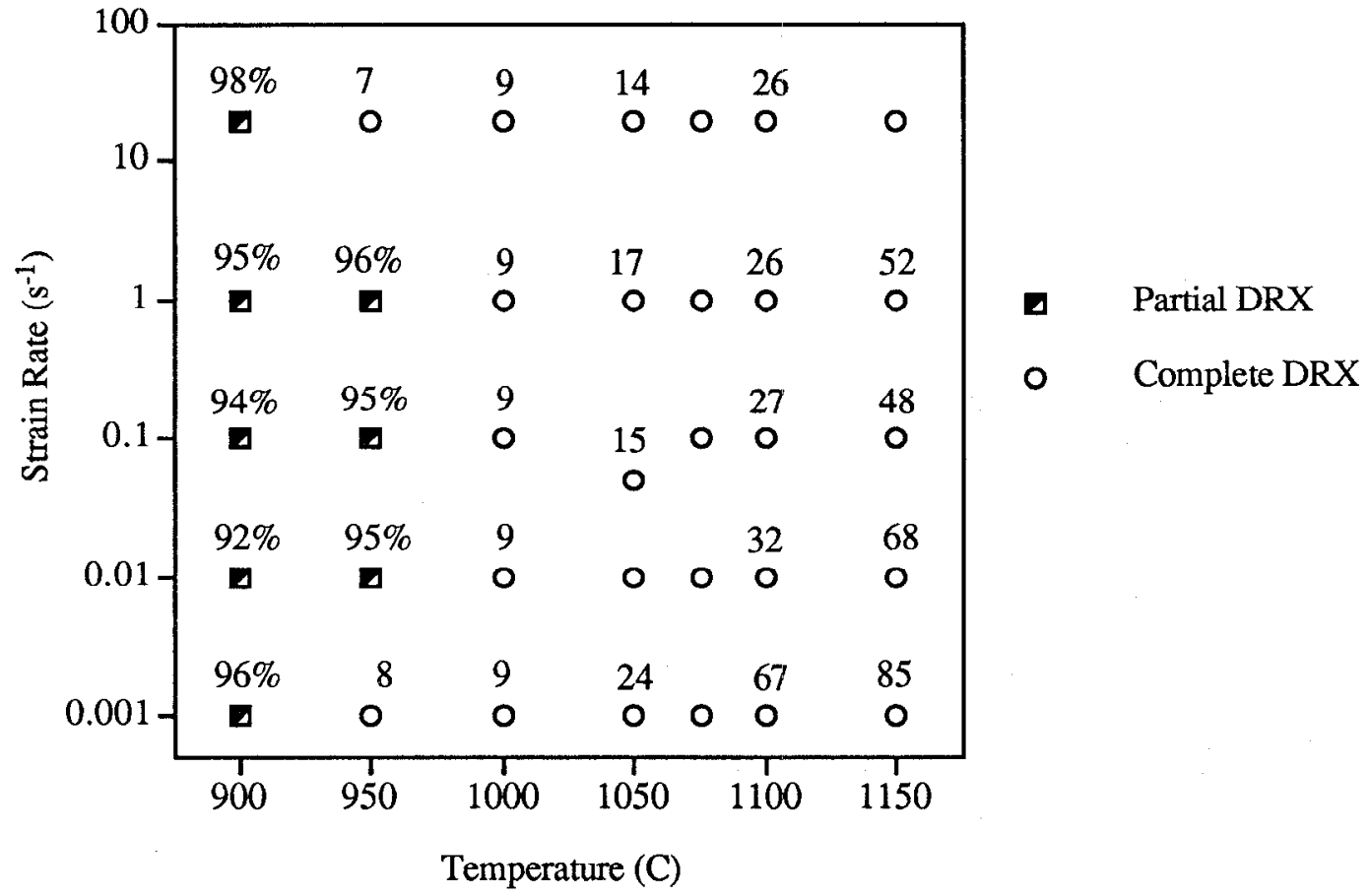

Figure 8 - Microstructural map summarizing as-deformed microstructures for Nickelvac 625 alloy deformed to a true strain of 0.6 ; percentage of DRX is shown for partially recrystallized microstructures, and grain size in $\mu \mathrm{m}$ is shown for completely recrystallized microstructure.

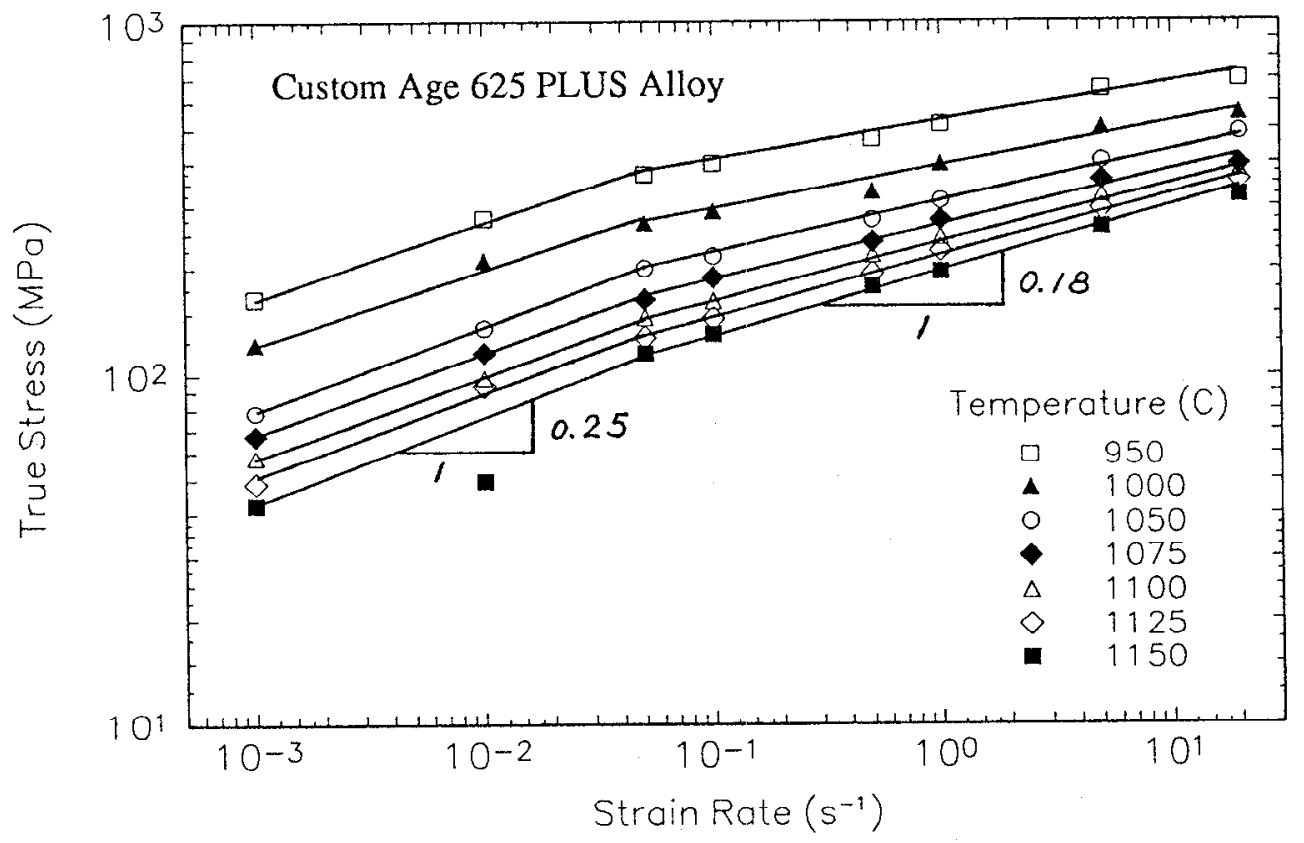

Figure 9 - Effect of strain rate on flow stress at a true strain of 0.5 for Custom Age 625 PLUS alloy.

Figure 9 shows the effect of strain rate on flow stress for Custom Age 625 PLUS alloy at a true strain of 0.5 . As shown in the figure, the $\log$ flow stress vs. $\log$ strain rate is bilinear except at 
one datum point. The slopes of the linear segments are the strain rate sensitivity values at different temperatures. At strain rates of $0.05 \mathrm{~s}^{-1}$ and below, these slopes are almost constant, approximately 0.25 for all temperatures. For higher strain rates, the slopes had some variation, especially at 950 and $1000 \mathrm{C}$ where the microstructure was partially recrystallized, but basically approached the value 0.18 at $1150 \mathrm{C}$, where the effect of deformation heating is minimum.

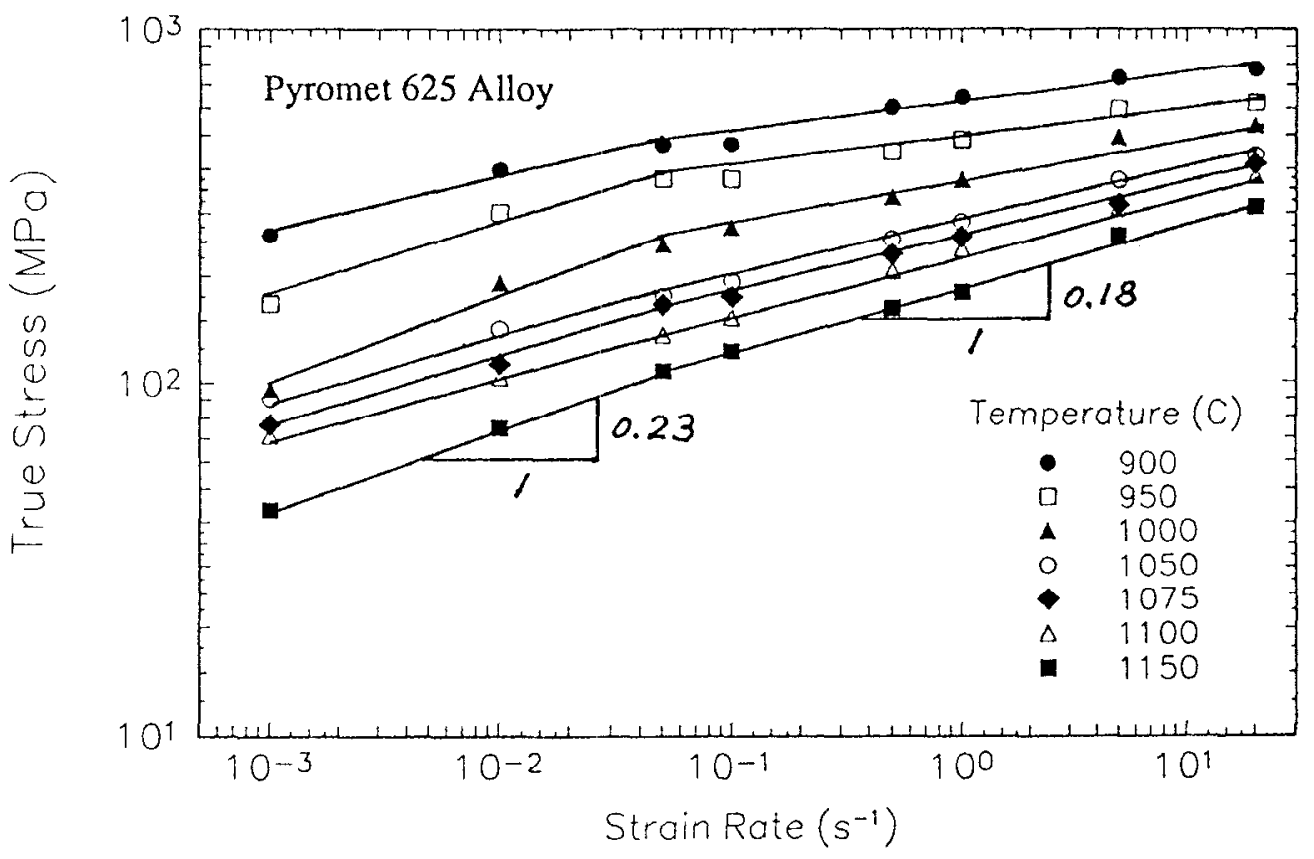

Figure 10 - Effect of strain rate on flow stress at a true strain of 0.5 for Pyromet 625 alloy.

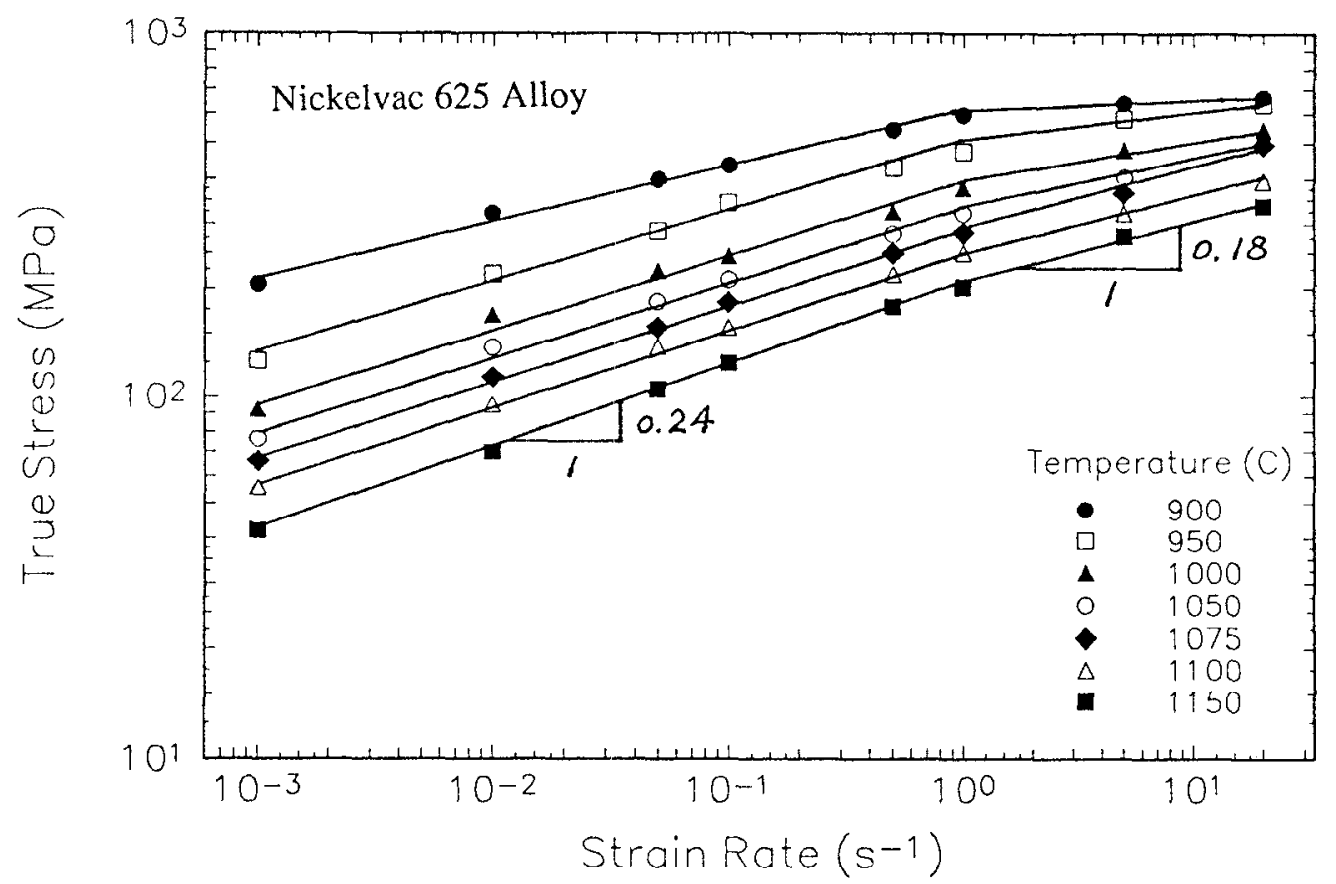

Figure 11 - Effect of strain rate on flow stress at a true strain of 0.3 for Nickelvac 625 alloy. 
Similar behavior was observed for Pyromet 625 alloy and Nickelvac 625 alloy. For Pyromet 625 alloy (Figure 10), the $\mathrm{m}$ values are equal to 0.23 for strain rates of $0.05 \mathrm{~s}^{-1}$ and below, at temperature $1150 \mathrm{C}$, and 0.18 for higher strain rates at the same temperature. For Nickelvac 625 alloy (Figure 11), the $\mathrm{m}$ values are 0.24 and 0.18 at $1150 \mathrm{C}$ for the two ranges of strain rate, but the transition strain rate was much higher, i.e. $1 \mathrm{~s}^{-1}$ compared to $0.05 \mathrm{~s}^{-1}$ for the other two alloys. Since high strain rate sensitivity indicates increased deformation uniformity, Nickelvac 625 alloy exhibited a larger range of strain rate for more uniform deformation than the other two alloys.

The effect of temperature on flow stress is shown in Figure 12 for Custom Age 625 PLUS alloy. The slope of this plot is related to apparent activation energy for plastic deformation. For most cases, the data fit a straight line without a significant difference in the slope. The fit appears to be very good considering the microstructural changes that took place during deformation as shown in microstructural map (Figure 6). It seems that the activation energy is constant over the temperature and strain rate ranges tested. The small decrease in the slope as strain rates approach $20 \mathrm{~s}^{-1}$ may merely be an effect of deformation heating. In fact, if deformation heating correction is applied to the stress values, the straight lines plotted at high strain rates tend to become parallel to those at low strain rates. Similar behavior was observed for Pyromet 625 alloy and Nickelvac 625 alloy, as shown in Figure 13 and Figure 14 respectively.

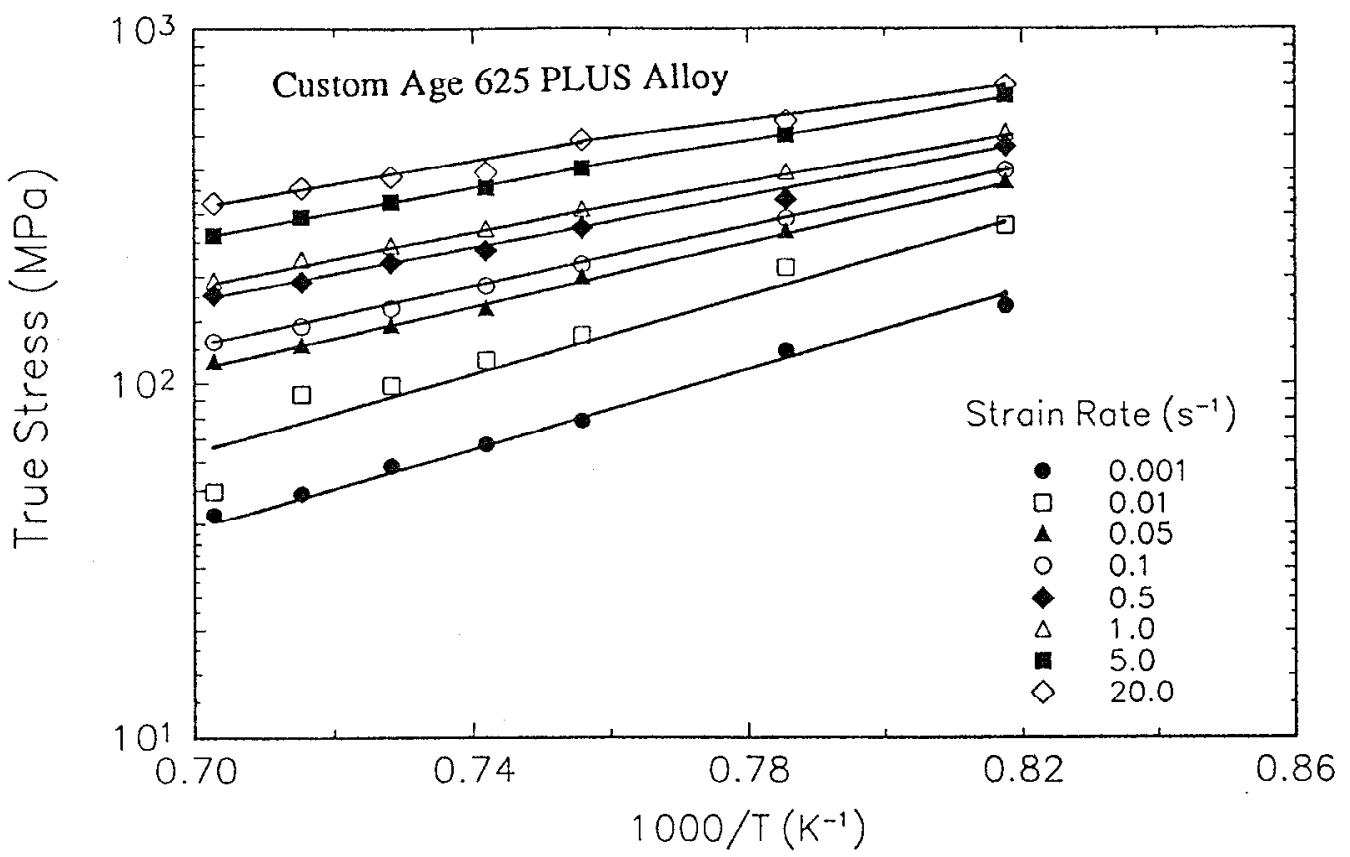

Figure 12 - Effect of temperature on flow stress at a true strain of 0.5 for Custom Age 625 PLUS alloy.

\section{Correlations of Flow Behavior and Microstructure}

The flow behaviors observed in all three alloys were closely related to the as-deformed microstructures. Macroscopic flow localization was not obvious, and the deformation was relatively uniform throughout the whole specimen. This is a result of the good lubrication condition, uniform temperature within the specimen, and relatively high strain rate sensitivity of the materials. The general feature of flow softening was mainly caused by DRX. All three alloys experienced DRX over the temperature and strain rate ranges tested. In general, both the flow behavior and the deformed microstructure were affected by temperature and strain rate. At low temperatures, partial recrystallization was favored and the peak of the flow curve occurred at higher strain value than that at higher temperatures. The smaller extent of flow softening after 
the peak at low temperatures is also consistent with the microstructure, because the partially recrystallized microstructure persists even at high strain values. At high strain rates, deformation heating also contributes significantly to flow softening. At high temperatures and low strain rates, slight flow hardening occurred after the first peak on the flow curves. These conditions correspond to the coarse grain in the as-deformed microstructure, and the hardening effect was due to the increased creep resistance as a result of grain growth.

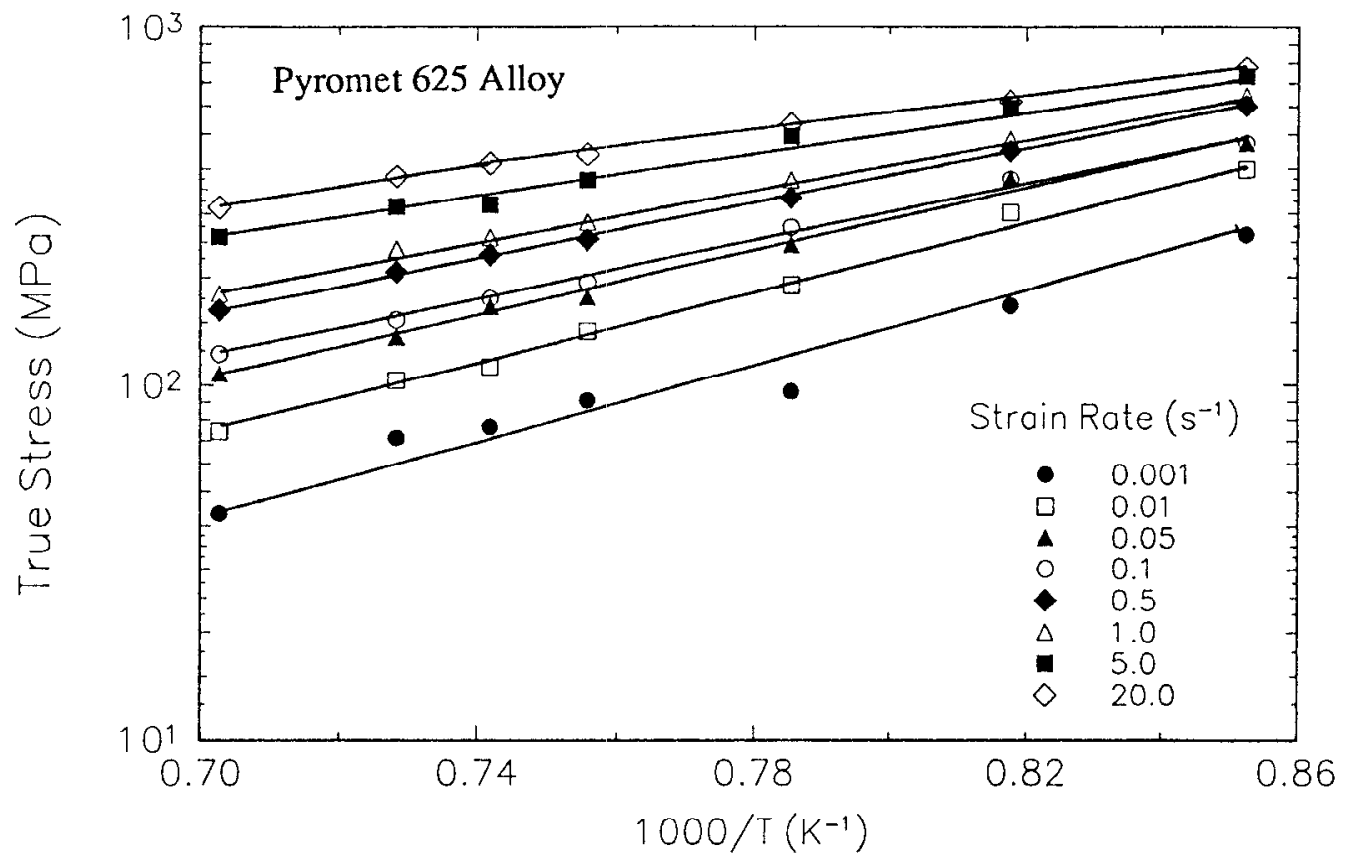

Figure 13 - Effect of temperature on flow stress at a true strain of 0.5 for Pyromet 625 alloy.

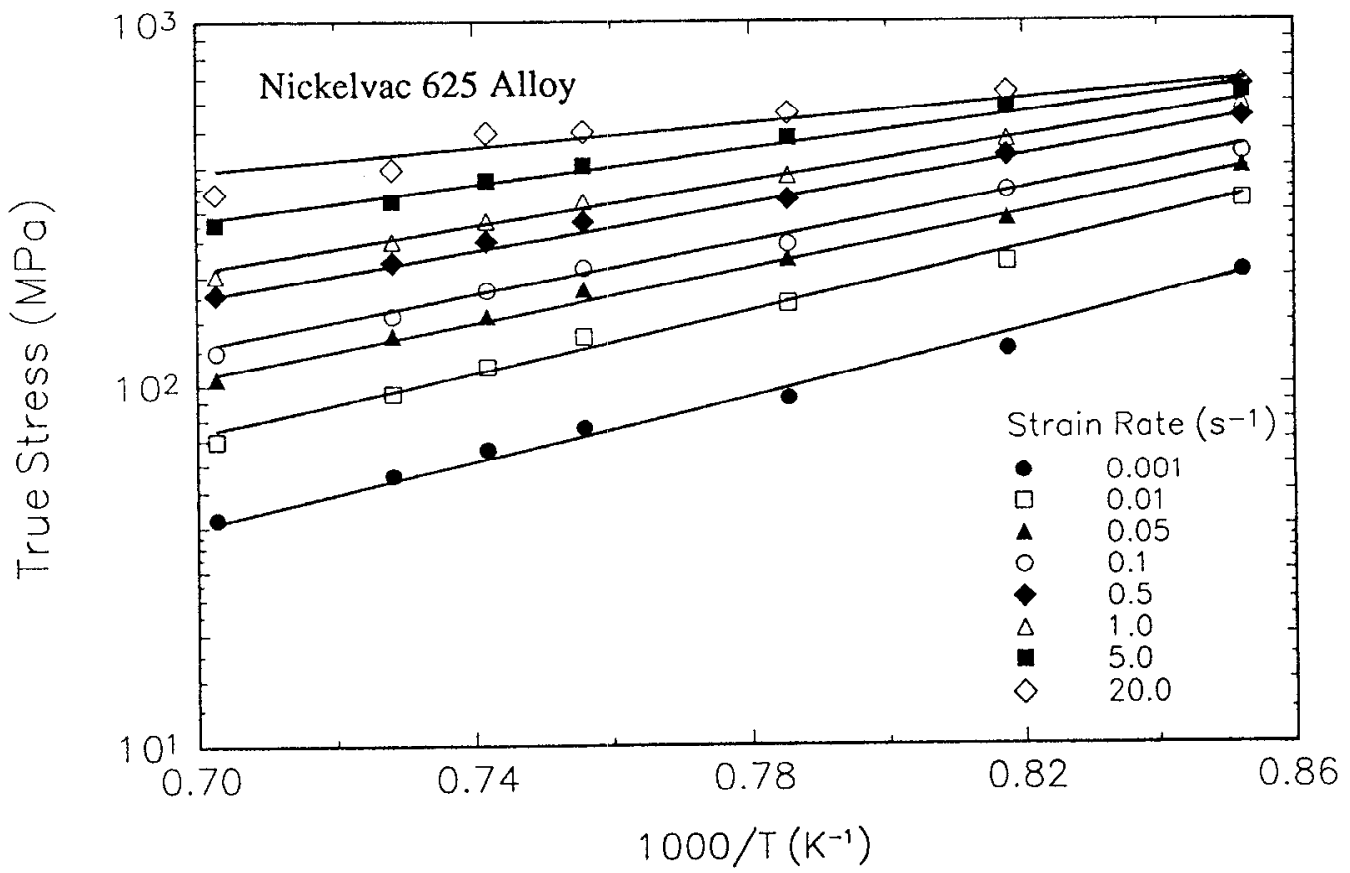

Figure 14 - Effect of temperature on flow stress at a true strain of 0.3 for Nickelvac 625 alloy. 
The overall similarity in flow behavior and microstructural evolution in the three alloys is obviously due to their similar chemical composition. However, the difference in microstructural changes, mainly DRX which occurred at different hot forming conditions for all three alloys was due to the small differences in alloy chemistry, precipitate size and distribution in the alloys. Recrystallization was complete at $1050 \mathrm{C}$ for Custom Age 625 PLUS alloy, $1000 \mathrm{C}$ for Pyromet 625 alloy, and essentially $900 \mathrm{C}$ for Nickelvac 625 alloy. Among the three alloys, Custom Age 625 PLUS alloy exhibited the most sluggish DRX kinetics, largest DRX grain size and fastest grain growth at the highest temperature and the lowest strain rate. This can be attributed to the very low carbon content in Custom Age 625 PLUS alloy, resulting in few $\mathrm{Nb}$ and Ti carbide precipitates, which act as nucleation sites for recrystallization and also restrict grain growth. Under the same conditions of forming, a higher percentage of recrystallization was observed in Pyromet 625 alloy than in Custom Age 625 PLUS alloy. The lowest temperature for complete recrystallization in Nickelvac 625 alloy is consistent with the highest carbon content and more uniform carbide distribution in this alloy. Further, there was evidence that fine, closely distributed $\gamma^{\prime \prime}$ and $\gamma^{\prime}$ precipitates inhibit recrystallization [7], which nnay also raise the complete recrystallization temperature of Custom Age 625 PLUS alloy (higher Ti).

In partially recrystallized microstructures, the onset of recrystallization through necklacing was evident, and the presence of grain boundary precipitate strings in Pyromet 625 alloy appeared to inhibit the necklacing. Actually the grain boundary precipitates in this alloy being very fine and closely spaced as strings, nucleate only subcritical grains that do not grow. The grain boundary as well as other carbide precipitates act as nucleation sites and help recrystallization as in the casc of Nickelvac 625 alloy, whose microstructure shows coarser and sparsely dispersed precipitates.

The percentage recrystallization in partially recrystallized microstructures varied with temperature and strain rate for all three alloys. At an intermediate strain rate, where the exposure time is short and the deformation heating is not significant, the alloys showed lowest percentage of recrystallization. Longer exposure time at lower strain rates, and deformation heating at high strain rates resulted in an increase in percent recrystallization. However, this trend is only true at temperatures $950 \mathrm{C}$ and above, because at lower temperatures, such as $900 \mathrm{C}$ for Pyromet 625 alloy, Figure 8 , longer exposure at temperature does not really help recrystallization. On the other hand, since deformation heating is more effective at low temperatures, the percentage recrystallization increased with increasing strain rate. At a given strain rate, increasing test temperature resulted in a higher percentage of recrystallization, as expected.

Finally, while the size and distribution of the carbide precipitates in these alloys dictated the size of the DRX grains, their growth after recrystallization was dependent on the deformation temperature and strain rate. At very high strain rates, although deformation heating causes some increase in temperature, there is not enough time for grain growth, and the grains remained small. In general, high temperature and low strain rate caused grain coarsening.

\section{Recommended Processing Conditions}

The selection of processing parameters for a given deformation process is dependent on the available equipment and other production considerations. In terms of uniform deformation (corresponding to high values of strain rate sensitivity) and resulting microstructure, recommendations can be made based on this investigation. Strain rates of $1 \mathrm{~s}^{-1}$ and below are recommended for uniform deformation. To obtain completely recrystallized fine grain microstructure, all three alloys can be processed at temperatures of 1000 to $1050 \mathrm{C}$. Strain rate has little effect on final grain size in this temperature range. If higher temperature must be used, intermediate strain rates such as 0.1 to $1 \mathrm{~s}^{-1}$ are recommended. By deforming the alloys at 1000 $\mathrm{C}$, an average grain size of $10 \mu \mathrm{m}$ (ASTM 10) or finer can be achieved.

\section{Summary and Conclusions}

Compression tests have been conducted on three 625 type superalloys over wide ranges of temperatures and strain rates to investigate the flow and microstructural behavior. The flow stresses of all three alloys were dependent on temperature, strain rate and the corresponding 
microstructure. The strain rate sensitivities are generally in the range of 0.15 to 0.25 for the three alloys. Flow softening, evident in all alloys has been mainly attributed to DRX, and partly to deformation heating at high strain rates. Grain growth at high temperatures and low strain rates resulted in slight flow hardening after the initial peak because of increased creep resistance. The completion of DRX, recrystallized grain size, and rate of grain growth were influenced by the alloy chemistry and microstructural features such as the amount, size, and distribution of the carbide precipitates.

Post-deformation microstructural maps have been developed. Two regions were identified: partial recrystallization and complete recrystallization. The recrystallization complete temperature was $950 \mathrm{C}$ for Nickelvac 625 alloy, $1000 \mathrm{C}$ for Pyromet 625 alloy, and $1050 \mathrm{C}$ for Custom Age 625 PLUS alloy. By considering both the as-deformed microstructure and the strain rate sensitivity, preferred processing conditions are strain rates of $1 \mathrm{~s}^{-1}$ and below and temperatures of 1000 to $1050 \mathrm{C}$ for the three alloys if completely recrystallized fine microstructure is desired.

\section{$\underline{\text { References }}$}

1. R.B. Frank and T.A. DeBold, Paper No. 75, NACE Corrosion ' 88 Conference, St. Louis, MO, 21-25 March 1988 .

2. Alloy Data Custom Age 625 PLUS ${ }^{\circledR}$ Alloy (Reading, PA: Carpenter Technology Corporation).

3. H.H. Ruble and S.L. Semiatin, Metals Handbook Ninth Edition (Metals Park, OH: ASM International, 1988), 261-266.

4. Atlas of Formability Bulletin for Custom Age 625 PLUS Alloy (Johnstown, PA: National Center for Excellence in Metalworking Technology (NCEMT), 1993).

5. Atlas of Formability Bulletin for Pyromet 625 Alloy (Johnstown, PA: National Center for Excellence in Metalworking Technology (NCEMT), 1993).

6. Atlas of Formability Bulletin for Nickelvac 625 Alloy (Johnstown, PA: National Center for Excellence in Metalworking Technology (NCEMT), 1993).

7. R.P. Singh, J.M. Hyzak, T.E. Howsen and R.R. Biederman, Superalloys 718, 625 and Various Derivatives, edited by E.A. Loria (Warrendale, PA: TMS, 1991), 205-215. 